they may be liquefied with ahout equal facility. It should be noticed that the thermal change accompanying the formation of any one of these gases, $\mathrm{HCl}$, for example, is not a true measure of the attraction between the atoms, since it also includes the heat employed in separating the atoms of the original molecules $\mathrm{H}_{2}$ and $\mathrm{Cl}_{22}$.

We may also find a confirmation of the above views in the many homologous series of organic chemistry. In the alcohols of the ethyl series, for example, the larger the molecules the greater must be the attraction between them, and consequently the higher the boiling-point; this, as is well known, is in accordance with fact. In the case of isomeric alc shols, the influence of the position of the atoms comes conspicuously to the fore. It is clear that if the atoms of carbon of two different molecules cannot approach each other so nearly in the case of one isomer as in another, the attraction between the molecules will be less, and the boiling-point consequently lower. Now in secondary and tertiary alcohols the carbon atoms are more sheltered by each other, are, as it were, more removed from the exterior of the molecule than in primary alcohols; at the same time the boiling-points are lower, which is as it should be.

If we replace two atoms of hydrogen in an alcohol by one of oxygen we increase the attraction of the molecules, since we substitute a certain number of attractions $(h o)$ and $(c o)$ for the relatively small attractions $(h h)$ and $(c h)$; the increase of boiling-point which we should expect is confirmed by experiment. Many other examples might be brought forward, were it not that their discussion would transcend the limits of this article.

Before concluding I should like to draw attention to one question which is of importance. The use of the above hypothesis renders it difficult at first sight to account for the formation of definite chemical compounds; it seems that if any number of atoms of hydrogen are equally attracted by one of chlorine, the combination of one of them with that atom would not prevent the adherence of a second and a third forming $\mathrm{H}_{2} \mathrm{Cl}, \mathrm{H}_{3} \mathrm{Cl}$, \&c. This difficulty is avoided by supposing that the chlorine atom is of such a form that only one atom of hydrogen can approach sufficiently closely to adhere permanently; such forms are difficult to imagine, though it may be remarked that an atom in the form of a ring offers in a certain sense a unique position to another which instals itself inside it. The existence of molecular compounds proves that the permanent adherence of other atoms is sometimes possible, and thus affords material support to the notion that the chemical affinity of an atom is not only exerted upon those atoms with which it is combined, but upon all others in its vicinity.

The Museum, Oxford

\section{THE GESTURE SPEECH OF MAN}

$A^{\text {NTHROPOLOGY tells the march of mankind out of }}$ savagery, in which different peoples have advanced in varying degrees, but all started in progress in civilisation from a point lower than that now occupied by the lowest of the tribes now found on earth. The marks of their rude origin, retained by all, are of the same number and kind, though differing in distinctness, showing a common origin to all intellectual and social development, notwithstanding present diversities. The most notable criterion of difference is in the copiousness and precision of oral speech, and connected with that, both as to origin and structure, is the unequal survival of gesture signs, which it is believed once universally prevailed. Where signlanguage survives it is, therefore, an instructive vestige of the prehistoric epoch, and its study may solve problems in philology and psychology. That study is best pursued by comparing the pre-eminent gesture system of the North American Indians with the more degenerate or less developed systems of other peoples.

North America showed more favourable conditions for the development of gesture signs than any other thoroughly explored part of the world. In the pré-Columbian period the population was scanty, and so subdivided dialectically that the members of but few bands could readily converse with each other. The sixty-five families of the Indian language now known to have existed within the territory of the United States differed among themselves as radically as each differed from the Hebrew, Chinese, or English. In each of these families there were sometimes as many as twenty separate languages, differing from each

${ }^{2}$ Address by Col. Garrick Mallery, U.S.A., Chairman of the Sub-Section of Anthropology at the American Association (Cincinnati). other as the Engli-h, French, German, and Persian divisions of the Aryan linguistic stock.

The conditions and circumstances attending the prevalence, and sometimes the disuse, of sign-language in North America were explained. The report of travellers, that among Indians, as well as other tribes of men, some were unable to converse in the dark, because they could not gesture, is false. It is the old story of aglossos and barbaros applied by the Greeks to all who did not speak Greek, repeated by Isaiah of the "stammering" Assyrians, and now appearing in the term slav (speaker) as contradistinguished by the Russians from the Germans, whom they stigmatise as njemez (tongueless).

The theory that sign-language was the original utterance of mankind does not depend upon such tales or prejudices. After the immeasurable period during which man has been upon the earth, it is not probable that any existing peoples can be found among whom speech has not obviated the absolute necessity for gesture in communication between themselves. The signs survive for convenience used together in oral language, and for special employment when language is unavailable.

The assertions made that the sign language of Indians originated from some one definite tribe or region supposes its comparatively recent origin, whereas the conditions favourable to its development existed very long ago and were co-extensive with the territory of North America occupied by any of the tribes. Such a solution would only be next in difficulty to the old persistent determination to decide upon the origin of the whole Indian race, in which most people of antiquity in the eastern hemisphere, including the lost tribe of Israel, the gypsies, and the Welsh, had figured conspicuously as putative parents. Numerous evidences were presented as to its antiquity and generality. But the signs are not now, and from the nature of their formation never were, identical and uniform.

An argument for the uniformity of the signs of Indians was derived from the fact that those used by any of them were generally understood by others. But signs might be understood without being identical with any before seen. There was evidence that where sign language was found among Indian tribes it had become more uniform than ever before, simply because many tribes had for some time past been forced to dwell near together at peace. The process of the formation and introduction of signs was the same among Indians as often observed among uninstructed deaf-mutes when associated together. There was a similarity of development between the sign language of mutes and Indians. The longer and closer the contact between Indians while no common tongue was adopted, the greater would be the uniformity of signs. The inference that there was but one true Indian sign language, just as there was but one true English language, was not correct, unless it could be shown that a much larger proportion of the Indians who use signs at all, than present researches show to be the case, used identically the same signs to express the same ideas, and also because the signs are not absolute and arbitrary, as are the words of English.

Are these signs conventional or instinctive? Sign language, as a product of evolution, had been developed rather than invented, and yet it seemed probable that each of the separate signs, like the several steps that lead to any true invention, had a definite origin arising out of some appropriate occasion, and th $\approx$ same sign might in this manner have had many independent origins due to identity in the circumstances, or, if lost, might have been reproduced. In regard to arbitrary or natural sounds, no signs in common use were in their origin conventional, and what appeared to be conventionality largely consisted in the form of abbreviation agreed upon. When the signs of the Indians had from ideographic become demotic, they might be called conventional, but still not arbitrary. Yet, while all Indians, as well as all gesturing men, have many signs in common, they use many others which have become conventional in the sense that their etymology and conception are not now known or regarded by those using them. The conventions by which such signs were established occurred during long periods and under many differing circumstances. Our Indians, far from being a homogeneous race and possessing uniformity in their language, religions, and customs, differ from each other more than all the several nations of Europe, and their semiotic conceptions have correspondingly differed. To insist that sign language was uniform were to assert that it is perfect. He next went on to prove the general ancient use of the system in North America. This fact might be recognised among tribes long exposed to 
European influence and officially segregated from all others. Collections had been obtained from the Iroquois, Ojibwas, Alaskans, Apaches, Tuni, Pimas, Papagos and Maricopas, after army officers, missionaries, Indian agents, and travellers had denied them to be possessed of any knowledge on the subject.

The studies so far pursued led to the conclusion that at the time of the discovery of North America all its inhabitants practised sign language, though with different degrees of expertness, and that while under clianged circumstances it was disused by some, others, in especial those who, after the acquisition of horses, became nomads of the great plains, retained and cultivated it to the high development now attained.

Instances were presented of the ascertained permanence of some Indian signs, and those of foreign peoples and deaf mutes. Though they, as well as words, animals and plants, have had their growth, development, and change, those which are genera both among Indian tribes, and are also found in other parts of the world, must be of great antiquity. Many signs but little differentiated were unstable, while others that have proved to be the best modes of expression have survived as definite and established.

The Indian system as a whole was compared with those of foreign peoples-the ancient Greeks and Romans and the modern Italians being first considered. His researches during several years showed a surprising number of signs for the same idea which were substantially identical not only among savage tribes, but among all peoples that used gesture signs with any freedom. This remark applied to the collections of signs already obtained by correspondence from among the Turks, Armenians, and Koords, the Bushmen of Africa, the Fijians, the Redjangs and Lelongs of Sumatra, the Chinese and the Australians. In com paring the Indian sign language with deaf mute signs, it was noticeable that the Indians who had been brought to the Eastern States had often held happy intercourse by signs with white deaf mutes, who surely had no semiotic code preconcerted with any of the plain roamers. Many of their signs were identical, and all sooner or later were mutually understood. The result of all these comparisons was that the so-called sign language of Indians was not, properly speaking, one language, but that it and the gesture systems of deaf mutes and of all people constituted together one language - the gesture speech of mankindof which each system is a dialect.

The most interesting light in which Indians, as other lower tribes of men, are to be regarded is in their present representation of the stage of evolution once passed through by our ancestors. Their signs, as well as their myths and customs, form a part of the palæeontology of humanity. Their picture writings are now translated by working on the hypothesis that their rude form of graphic representation, when at the same time a system of idiographic gesture signs prevailed, would probably have been connected with the latter. Traces of the signs now used by the Indians are also found in the ideographic pictures of the Egyptian, Chinese, and Aztec characters.

Signs often gave to spoken words their first significance, and many primordial roots of language are found in bodily actions. Examples were given of English, Indian, Greek, and Latin words in connection with gesture signs for the same meaning, and the structure of the sign language was compared with the tongues of this continent, and with reference also to old Asiatic and African languages, showing similar operations of conditions in the same psychologic horizon.

The most obvious application of sign language for its practical utility depended iupon the correctness of the view submitted, that it is not a mere semaphoric repetition of motions to be memorised from a limited traditional list, but a cultivable art, fotnded upon principles which can be readily applied by travel. lers. The advantage was not merely theoretical, but had been demonstrated to be practical by a professor in a deaf-mute col lege; who, lately visiting several of the wild tribes of the plains, made himself understood among all of them without knowing a word of any of their languages, and by another who had a similar experience in Italy and Southern France.

The powers of sign language were then compared with those of speech. It finds actually in nature an image by which any person can express his thoughts and wishes on the most needful subjects to any other person. Merely emotional sounds may correspond with merely emotional gestures, but whether with or without them would be useless for the explicit communication of facts and opinions of which signs themselves are capable. Notwithstanding frequent denials, they do possess abstract ideas.
The rapidity of communication is very great, and can approach to that of thought. Oral speech is now conventional, and with the similar development of sign-language conventional expressions could be made with hands and body more quickly than with the vocal organs, because more organs could be worked at once.

But such rapidity is only obtained by a system of preconcerted abbreviations and by the adoption of absolute forms, thus sacrificing self-interpretation and naturalness.

Sign-language was superior to all others in that it permitted every one to find in nature an image to express his thoughts on the most needful matters intelligibly to any other person. The direct or substantial natural analogy peculiar to it prevented a confusion of ideas. Successful signs must have a much closer analogy and establish a rapport between the talkers far beyond that produced by the mere sound of words. If they had been elaborated by the secular labour devoted to spoken language, man could by his hands, arms and fingers, with facial and bodily accentuation, express any idea that could be conveyed by words. The very concepts of plurality, momentum, and righteousness could be clearly expressed by signs, and it is not understood why those signs could not have obtained their present abstract signi ficance through the thoughts arising from the combination and comparison of other signs, without words. When highly cultivated, the rapidity of sign language on familiar subjects exceed. that of speech, and approaches to that of thought itself.

From the records of the ancient classic authors and also from the figures on Etruscan vases and Herculanean bronzes and other forms of archaic art, it is certain that a system of gesturelanguage is of great antiquity. Later, Quintilian gave elaborate rules for gesture which are specially notable for the significant disposition of the fingers still prevailing in Naples. The ancient and modern pantomimes were discussed, and also the gestures of speaking actors in the theatres, the latter being seldom actually significant or self-interpreting even in the expression of strong emotion. The same scenic gesture must apply to many diverse conditions of fact. Its fitness consists in being the same which the hearer of the expository words would spontaneously assume if yielding to the same emotions, and which, therefore, by association tends to induce sympathetic yielding. But the facts themselves depend upon the words uttered. A true signlanguage would express the exact circumstances with or without any exhibition of the general emotion appropriate to them.

It is necessary to be free from the vague popular impression that some oral language of the general character of that now used by man is "natural" to man. There is no more necessary connection between ideas and sounds, the mere signs of words that strike the ear, than there is between the same ideas and signs for them which are addressed only to the eye. Early concepts of thought were of direct and material characters, as is shown by what has been ascertained of the radicals of language, and there does not seem to be any difficulty in expressing by gesture all that could have been expressed by those radicals.

It will be admitted that all the higher languages were at some past time less opulent and comprehensive than they are now, and as each particular language had been thoroughly studied, it had become evident that it grew out of some other and less advanced form. The discussion of philological subjects at the present day was varied by the suggested possibility that man at some time might have existed without any oral language. A proof of this assumption lay in the fact that uninstructed deaf mutes originated signs from time to time expressive of their wishes and ideas.

The doctrine of Archbishop Whately and Max Muiller, that deaf mutes could not think until after instruction, was combated. No one now doubts that the deaf mute thinks after instruction either in gesture signs or in the finger alphabet, or more lately in visible speech. By this instruction he has become master of a new and foreign language, but that he obtained from signs. But no one can learn a foreign language unless he had one of his own, whether by descent or acquisition, by which it could be translated, and such translation could not even be commenced unless the mind had been already in action, and intelligently using the original language for that purpose. In fact the use by deaf mutes of signs originating in themselves shows a creative action of mind and innate faculty of expression beyond that of speakers who acquired language without conscious effort.

It may be conceded that after man had all his present faculties he did not choose between the adoption of voice and gesture, and never with those faculties was in a state where the one was 
used to the absolute exclusion of the other. The epoch, however, to which the present speculations relate is that in which he had not reached the present symmetric development of his intellect and of his bodily organs, and the inquiry is, Which mode of communication was earliest adapted to his simple wants and informed intelligence? With the voice he could imitate distinctively but few sounds of nature, while with gesture he could exhibit actions, motions, positions, forms, dimensions, directions, and distances, with their derivations and analogues. It would seem from this unequal division of capacity that oral speech remained rudimentary long after gesture had become an efficient mode of communication. With due allowance for all purely imitative sounds, and for the spontaneous action of vocal organs under excitement, it appears that the connection between ideas and words is only to be explained by a compact between speaker and hearer which supposes the existence of a prior mode of communication. This was probably by gesture. At least we may accept it as a clue leading out of the labyrinth of philological confusion, and regulating the immemorial quest of man's primitive speech.

\section{SCIENTIFIC SERIALS}

Verhandlungen des naturhistorischen Vereines der Preussischen Rheinlande und Westfalens, 1881. Zweite Hälfte.-We note here the following :-On some Anthozoa of the Devonian, by Prof. Schlüter.--The Stromatopora of the Rhenish Devonian, by Herr Bargatsky.-Geological sketch of a journey through ralestine and the Lebanon region, by Prof. von Rath.-On the building art of birds, reduced to its true value, by Prof Landois. -The beetle genus Bruchus, Linn., and especially Bruchus pisorum, Linn., by Herr Cornelius. - On new finds of saurian tracks in the Wealden Sandstone of the Buickeberg, by Herr Grabbe.-The Royal Mercury Works at Idria, by Herr Fabricius.-The zinc ore deposits of Wiesloch, by Herr von Decken.-Bone-remains from the Schipka Cave in Moravia, by Prof. Schaaffhausen.-Removal of an iron fragment from the eyeball with an electromagnet, by Dr. Samuelsohn.-Skulls from Kirchheim, by Prof. Schaaffhausen.-Influence of the use of transportable pneumatic apparatus on the circulation of a healthy man, by Prof. Finkler.- - On a colossal femur of the horse, found in January, I88o, when removing part of a bank of the Wupper at Elberfeld, by Prof. Schaaffhausen.-On socalled cosmic dust from Dresden, by Prnf, von Lasaulx. - New apparatus for continuous application of weak galvanic currents, by Prof. Finkelnberg.-On the earthquake of Ischia, March 4, I88I, by Prof, von Rath.-On eruptive gneiss in Saxony and Bavaria, by Dr. Lehmann.-Nerve-stretching ; three cases, by Prof. Doutrelepont.

\section{SOCIETIES AND ACADEMIES LONDON}

Aëronautical Society, July 17.-A paper, upon the action of the pectoral muscle in the flight of a bird, was read by $\mathrm{Mr}$. Fred. W. Brearey. He said that it behoved all experimenters in flight to reduce their theories into a demonstrable form. It had often been stated for instance that the power exerted by a bird in its flight had been greatly exaggerated, but no one had hitherto proved his assertion. It was carable however of satisfactory proof by demonstrating artificially the action of the pectoral muscle, by the aid of which weight became an accessory to power. When the bird committed itself to the air the upward pressure in the wings stretched the elastic ligament, which formed part of the muscle, to such an extent as to allow of the bird gliding upon the air without any exertion. The weight of the bird was the measure of this elasticity. It was said by some that at least the bird must possess the power by the downward stroke of the wing to raise its own weight. But Mr. Brearey said that this was not an absolute necessity, because the reaction of this elastic ligament aided the force of the down stroke. He proceeded to verify his assertion by the action of a model, with wings of four feet spread, under which he had at tached an elastic cord passing under the body of the model. Upon committal to the air this just allowed of the wings being expanded, so that the model would glide downwards. He then detached the cord and wound up his power, calling attention to the fact that he had wound the india-rubber strands thirty-two times. He showed however that although this was sufficient to create a vigorous flapping of the wing when held in the hand, yet when committed to the air it had not the power to give one downward stroke, and therefore it could only glide as before. Holding it again with the cord attached and the power wound up the same number of times, he showed that it was unable to flap the wing, because the two forces were exactly held in equilibrium. There was a third factor wanted before it could fly-and that was weight. The model being liberated, flight was well sustained, and upon being set free several times without being wound up any further, it appeared able to fly with a very weak power. The same thing was observable with another model, composed entirely of a loose surface thrown into a wave action-his own invention. $\mathrm{Mr}$ Brearey remarked that this economy in flight can only be obtained by something of the nature of wing action, and must be wholly wanting in any apparatus actuated by the screw.

\section{EDINBURGH}

Royal Society, July 17.- Prof. Balfour, vice-president, in the chair.-Prof. Heddle read a paper on the sequence of rocks in the North-West Highlands, a point on which there had been and still was a great deal of controversy. The author had examined eighteen sections in the region around and to the north of Loch Maree, and had convinced himself that Murchison and Geikie were in the main correct. The succession of the rocks was found to be as follows:-Torridon Conglomerates, Lower Quartzite, Dolomite Series, "Logan" Rock, Upper Quartzite, Upper Gneiss. The dolomite does not extend so far west as the quartzite and Logan Rock, and is of no great lateral extent, but it stretches as a thin strip of shallow water deposit from end to end of the whole district.-Prof. Tait communicated a paper by Mr. Wm. Peddie on the rotation of plane of polarisation by quartz and its relation to wave-length. The spectrum of a ray of light which has been transmitted through the polariser, a piece of quartz, and the analyser, exhibits one or more absorption bands (the number depending upon the thickness of the quartz), which move along the spectrum as the analyser is rotated. By direct comparison of this spectrum with the ordinary solar spectrum in juxtaposition, the rotation for any Fraunhofer line can be estimated with considerable accuracy. The rotations were expressed in terms of the inverse even powers of the wavelengths as far as the sixth.-Mr. W. W. J. Nicol, in a paper on the condition of ammonium salts when dissolved in water, explained the abnormal expansion of solutions of ammonium chloride and other ammonium salts by the partial dissociation on solution in water-an explanation suggested by the well-known fact that such salts become acid on boiling. This view of the matter seemed further to explain other anomalies in the behaviour of ammonium chloride solution-such for example as its surface tension investigated by Quincke, and its coefficient of absorption for carbon dioxide as determined by Mackenzie. - Mr. J. Y. Buchanan described a new form of solar calorimeter which he had used in Upper Egypt at the time of the last eclipse. The sun's rays were concentrated by suitable reflectors upon a glass tube, two inches long, which formed the upper end of a Liebig's condenser, and was mounted equatorially so as to follow the sun's motion. The heat was measured by the amount of water distilled in a given time. The results obtained were very satisfactory, agreeing with the resulıs given by other methods.-Prof. Crum Brown read a continuation of the paper by Messrs. Laurie and Burton, on the heats of combination of the metals with the halogens, estimated from electromotive force observations. Their result for the heat of combination of zinc with iodine in the presence of water differed by barely 2 per cent. from Andrews' value. Other results did not agree so well; but this was hardly surprising where so many factors entered into the experiments. The most accurate method was no doubt to let a chlorine, iodine, or bromine cell with given poles run down in a calorimeter and estimate the heat so given out. -Professor Brown also communicated a long paper by $\mathrm{Mr}$. W. L. Goodwin, on the nature of solution, in which the author made a careful investigation into the solution of chlorine in various liquids at different temperatures. Experiment showed that there was in many cases a temperature of maximum solubility, a fact which Mr. Goodwin explained as due to the formation at lower temperatures of a chlorine hydrate whose rate of increase of solubility with increase of temperature quite masked the simultaneous decrease of solubility of the gas until a temperature was approached at which the chlorine hydrate could no longer exist.-The second part of the description of new and little-known phanerogamous plants from Socotra, by Prof. Bayley Balfour, was received as read.-The chairman, in bringing to a close the hundredth session of the Society, gave a brief review of the session's work. 